\title{
Transcriptome Analysis of Kiwifruit in Response to Pseudomonas syringae pv. actinidiae Infection
}

\author{
Tao Wang, Gang Wang, Zhan-Hui Jia, De-Lin Pan, Ji-Yu Zhang * and Zhong-Ren Guo \\ Institute of Botany, Jiangsu Province and Chinese Academy of Sciences, Nanjing 210014, China; \\ immmorer@163.com (T.W.); wg20092011@163.com (G.W.); 13915954315@163.com (Z.-H.J.); \\ PPxsperfect@163.com (D.-L.P.); zhongrenguo@cnbg.net (Z.-R.G.) \\ * Correspondence: maxzhangjy@cnbg.net; Tel.: +86-025-8434-7033
}

Received: 21 November 2017; Accepted: 23 January 2018; Published: 26 January 2018

\begin{abstract}
Kiwifruit bacterial canker caused by Pseudomonas syringae pv. actinidiae (Psa) has brought about a severe threat to the kiwifruit industry worldwide since its first outbreak in 2008. Studies on other pathovars of $P$. syringae are revealing the pathogenesis of these pathogens, but little about the mechanism of kiwifruit bacterial canker is known. In order to explore the species-specific interaction between Psa and kiwifruit, we analyzed the transcriptomic profile of kiwifruit infected by Psa. After 48 h, 8255 differentially expressed genes were identified, including those involved in metabolic process, secondary metabolites metabolism and plant response to stress. Genes related to biosynthesis of terpens were obviously regulated, indicating terpens may play roles in suppressing the growth of Psa. We identified 283 differentially expressed resistant genes, of which most U-box domain containing genes were obviously up regulated. Expression of genes involved in plant immunity was detected and some key genes showed differential expression. Our results suggest that Psa induced defense response of kiwifruit, including PAMP (pathogen/microbe-associated molecular patterns)-triggered immunity, effector-triggered immunity and hypersensitive response. Metabolic process was adjusted to adapt to these responses and production of secondary metabolites may be altered to suppress the growth of Psa.
\end{abstract}

Keywords: kiwifruit; bacterial canker; Psa; resistance

\section{Introduction}

Kiwifruit bacterial canker disease was first reported on Actinidiae chinesis var. deliciosa in Shizuoka, Japan in 1984 [1]. In 2010, the pathogen Pseudomonas syringae pv. actinidiae (Psa) was detected in New Zealand, and within two years it infected $37 \%$ of New Zealand orchards and continues to increase [2]. To date, Psa has been detected in the main kiwifruit producing countries, including China, Chile, and European countries [3,4]. Pathovars of the species P. syringae cause important diseases in a wide range of plant species. To look for the way to control these diseases, researchers worldwide are trying to find the pathogenesis of $P$. syringae. Plants hold a complete immune system which is composed of two lines of defense. The first is PAMP-triggered immunity (PTI), which recognizes molecular microbial determinants, termed pathogen/microbe-associated molecular patterns (PAMPs/MAMPs), via pattern recognition receptors (PPRs) [5]. The second line is termed effector-triggered immunity (ETI) which detects injected effector proteins in the cytoplasm by resistance proteins and elicits further immunity. PTI and ETI can combine to cause hypersensitive response (HR) at infection site, which involves programmed cell death.

Studies on the pathogenesis of Psa are limited, but works on other pathovars of P. syringae especially the model species P. syringae pv. tomato DC3000 give us the chance to view the interactivity between $P$. syringae and the host. A functional hypersensitive response and pathogenicity (hrp 
pathogenicity island [PAI]) type III secretion system (T3SS) that directs the delivery of effector proteins into host cells has been shown to be the key pathogenicity factor required for $P$. syringae to colonize and parasitize host plants [6]. Plant immune system is a major target of type III effectors. P. syringae suppresses plant immune system by translocating immune-suppressing effector proteins through T3SS into plant cell [7]. Although effector proteins suppress immunity in some plants, in other plants, they trigger ETI [8] upon their recognition by cognate resistance proteins which, in turn, activate a secondary defense reaction HR [9].

The genome of Psa has been analyzed by different groups and genes possibly involved in pathogenesis were identified. McCann and his colleagues [10] identified 51 known type III effectors from four different clades of Psa and only 17 were found in all Psa genomes. This raised the possibility that the capacity to cause disease in kiwifruit resided primarily in the core genome of Psa. Meanwhile Psa also displayed a set of genes involved in degradation of lignin derivatives and other phenolics [11]. In-depth studies on Psa genomes have shown that this pathovar can rapidly adapt to a new host and new environments through the acquisition and/or loss of mobile genetic elements and virulence factors, thereby resulting in a multi-faceted plant pathogen [12]. In this study we analyzed the transcriptomic profile of kiwifruit infected by Psa, hoping to explore the response of kiwifruit on the molecular level and to lay foundation for understanding the pathogenesis of kiwifruit canker disease.

\section{Results}

\subsection{De Novo RNA-Seq Assembly and Annotation of Unigenes}

The valid reads from all samples were merged for de novo assembly using trinity software. A total of 110,134 unigenes with a N50 of 1226 bp were obtained (Table 1). All unigenes were longer than $200 \mathrm{bp}$ and the average length was $759 \mathrm{bp}$. Functional annotation of unigenes were performed by blasting against various databases. Of all the 110,134 unigenes, 50,305 (45.68\%) matched to known sequences, with 49,897 (45.31\%) matching to sequences in $\mathrm{Nr}$ (non-redundant protein sequences) database, 34,331 (31.17\%) matching to Swissprot database, 30,430 (27.63\%) matching KOG (Clusters of eukaryotic ortholog groups of proteins) database, 20,524 (18.64\%) matching KEGG (Kyoto encyclopedia of genes and genomes) database.

Table 1. Functional annotation of the kiwifruit unigenes.

\begin{tabular}{ccc}
\hline Database & Number of Unigenes & Percentage \\
\hline Nr & 49,897 & 45.31 \\
Swissprot & 34,331 & 31.17 \\
KOG & 30,430 & 27.63 \\
KEGG & 20,524 & 18.64 \\
Annotation gene & 50,305 & 45.68 \\
Without annotation gene & 59,829 & 54.32 \\
Total unigenes & 110,134 & 100.00 \\
\hline
\end{tabular}

Nr: non-redundant protein sequence; KOG: Clusters of eukaryotic ortholog groups of proteins; KEGG: Kyoto encyclopedia of genes and genomes.

\subsection{Functional Classification of Unigenes}

To better understand functions of the unigenes, we did GO (Gene Ontology) analysis and categorized the 20,524 unigenes matching to KOG database into three GO trees (biological processes, cellular components, and molecular functions), which were further classified into 48 functional groups (Figure 1). The three groups with the most number of unigenes in the category of biological process were cellular process, metabolic process and single-organism process. Groups with the most unigenes in cellular component were cell, cell part and organelle. Binding and catalytic activity were the biggest groups in molecular function. 


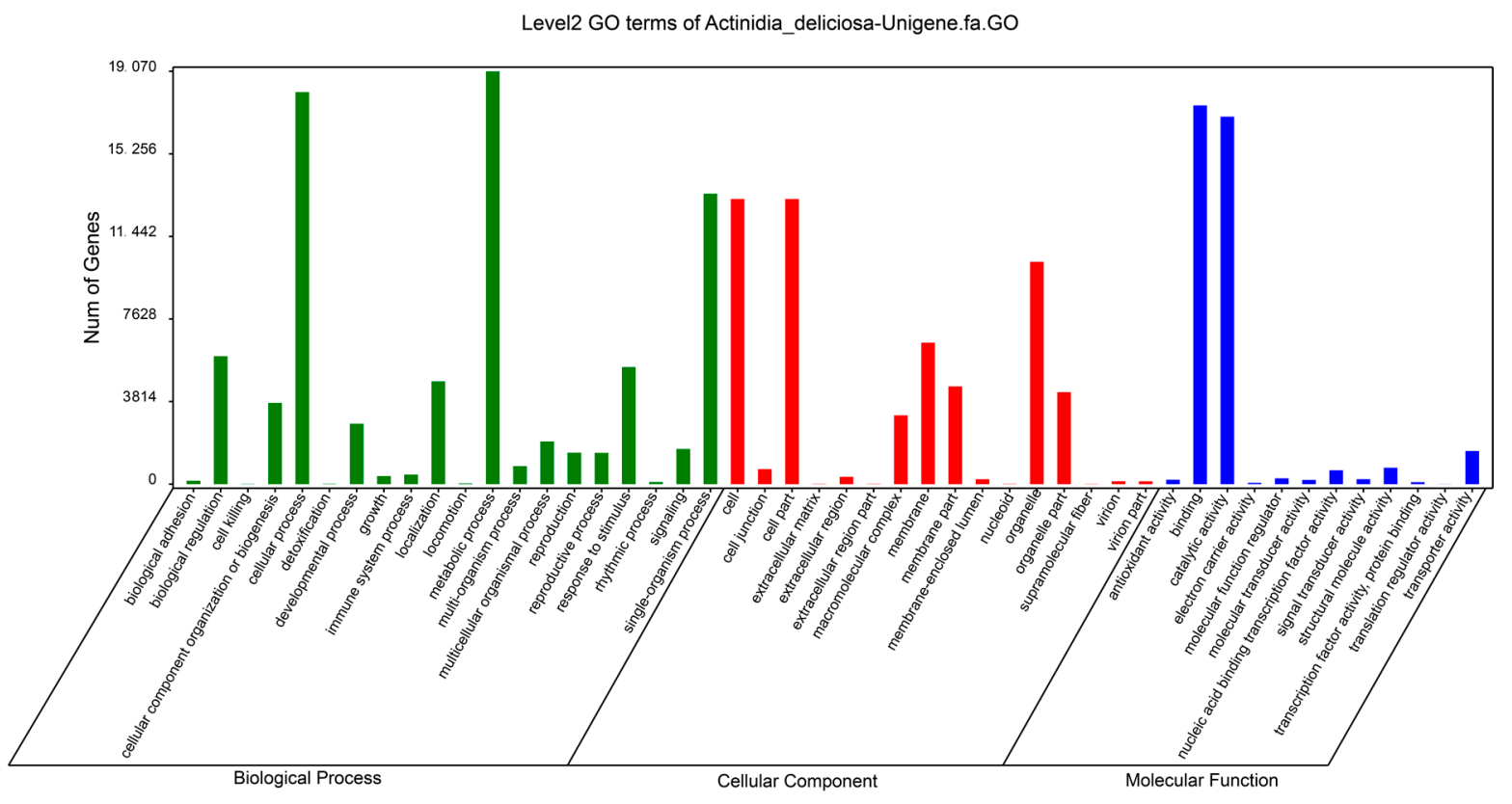

Figure 1. Gene Ontology classification of unigenes.

\subsection{Analysis of Differentially Expressed Unigenes}

Expression level of each unigene was calculated and differentially expressed genes (DEGs) between Psa-treated sample and control at 48 and $96 \mathrm{~h}$ time points were identified. Cluster analysis of unigenes of the five samples was done (Figure 2). Compared with the other four samples, expression pattern of CK was obviously different and presented the most number of DEGs. PY3, XJ3, PY4, and XJ4 gradually showed more expression differences.

Twelve unigenes were randomly selected for qRT-PCR analysis (Figure S1) to validate the results of the RNA sequencing data. All of the selected unigenes exhibited similar expression patterns to those from RNA sequencing data, so indicating that the results of RNA sequencing were credible.

\subsection{Functional Classification of Differentially Expressed Genes}

Enrichment and classification of the DEGs were performed by searching GO and KEGG database (Tables S1 and S2). In the category of biological process, GO terms of cellular process, metabolic process and single-organism process enriched the most DEGs (Figure 3). In the category of cellular component, cell, cell part and organelle part enriched the most DEGs. Binding and catalytic activity got the most DEGs in the category of molecular function. Most of GO terms in the category of biological process had more DEGs up regulated by Psa treatment than those down regulated, and it was the opposite case in the cellular component category.

We compared the expression patterns between Psa-treated samples and control at 48 and $96 \mathrm{~h}$ respectively. There were totally 8255 (7.50\%) DEGs (Table S3) between PY3 and XJ3, of which 2733 DEGs were down regulated in XJ3 relative to PY3, and 5522 DEGs were up regulated. Only 4281 DEGs (Table S4) were identified between PY4 and XJ4, and the numbers of DEGs down regulated and up regulated were similar. Among the most differentially expressed genes between PY 3 and XJ3, we identified DEGs participating in terpene synthesis, salicylic acid-binding, jasmonate, disease resistance, ethylene response and WRKY transcription factor which were all related to disease resistance of plant. There were also many DEGs participating in biosynthesis of secondary metabolites, environmental adaptation and carbohydrate metabolism. 


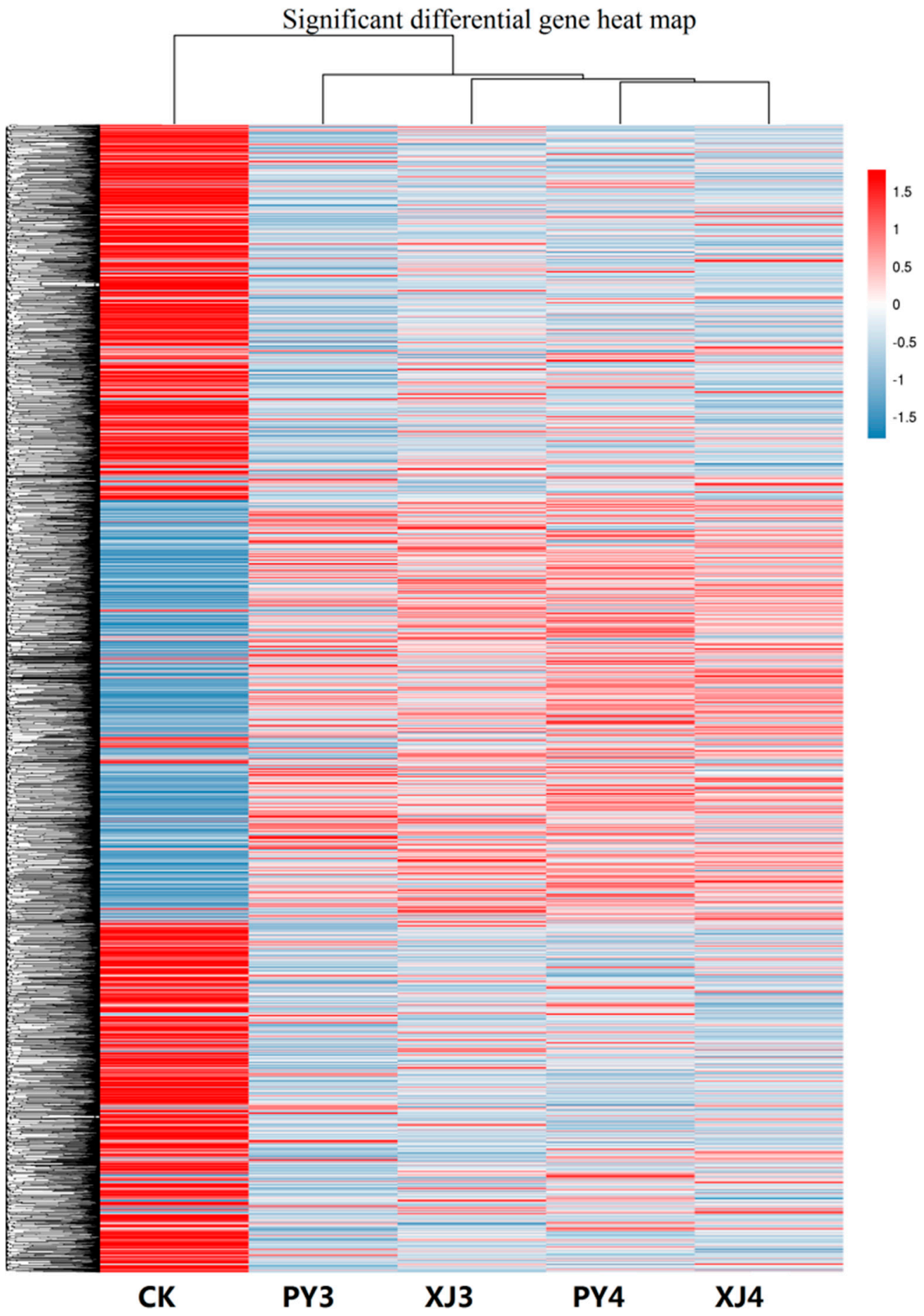

Figure 2. Cluster of significant differentially expressed genes of the five experimental samples. The RPKM (reads per kb per million reads) values of unigenes were used for hierarchical cluster analysis. Expression level was showed by different colors, the redder the higher expression and the bluer the lower. Five treatments were set: CK, only carved; PY3, inoculated with water and sampled $48 \mathrm{~h}$ after inoculation; PY4, inoculated with water and sampled at $96 \mathrm{~h}$; XJ3, inoculated with Psa and sampled at $48 \mathrm{~h}$; XJ4, inoculated with Psa and sampled at $96 \mathrm{~h}$. 


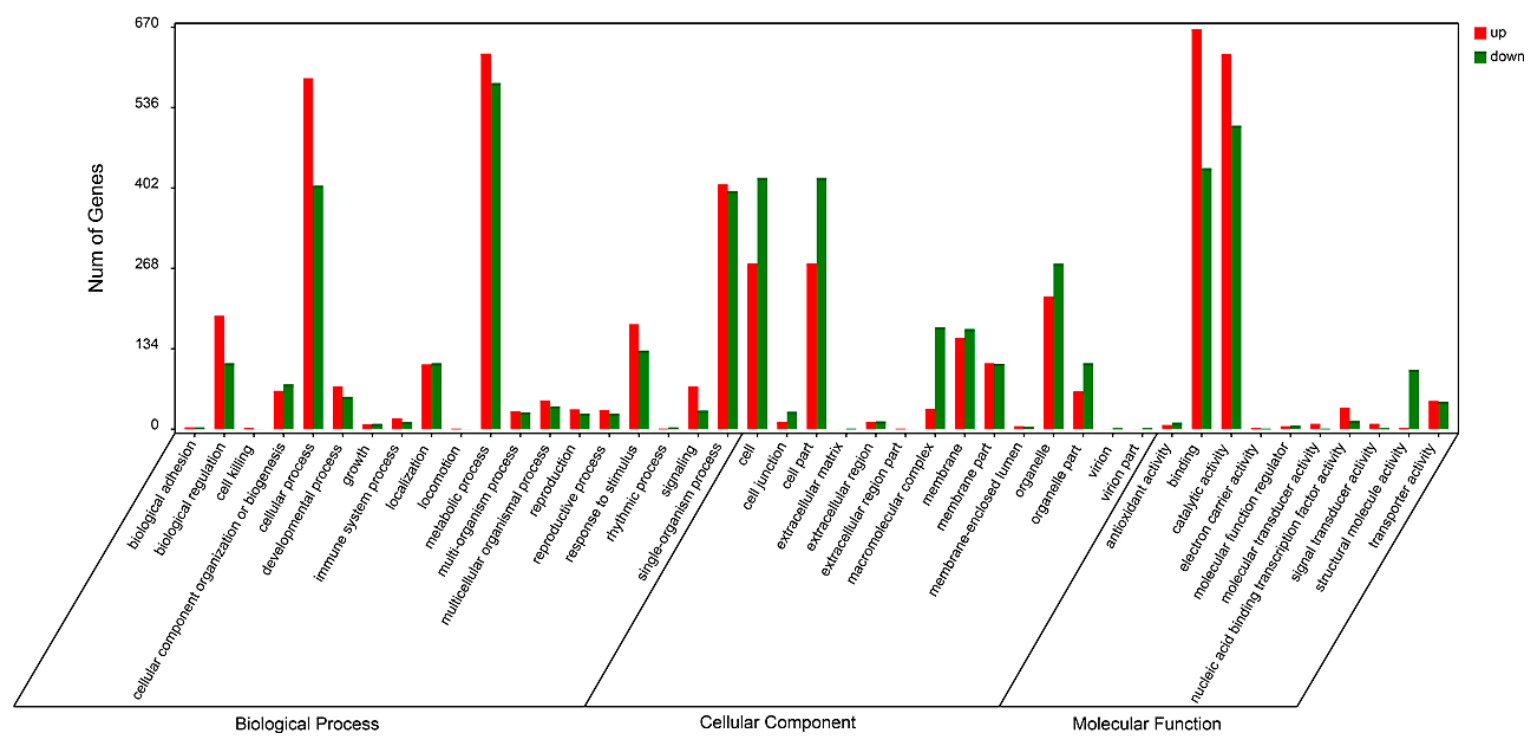

Figure 3. GO classification of differentially expressed genes.

The top 20 progresses influenced by Psa treatment were summarized in Table 2. The top one and top four progresses were both related to terpene metabolism. Metabolic process enriched the most abundant DEGs (1203) in the 20 progresses. Four of the 20 progresses: regulation of defense response, regulation of response to stress, response to bacterium, and regulation of multi-organism process were directly related to plant response to stress. KEGG analysis resulted that the pathway of translation was the mostly influenced pathway and enriched the most abundant DEGs in the top 20 pathways. Other pathways influenced by Psa treatment included metabolism of terpenoids, polyketides, and other secondary metabolites, and metabolism of carbohydrate, amino acid, and lipid.

Table 2. The enriched differential progress top 20.

\begin{tabular}{|c|c|c|c|}
\hline GO ID & Description & $\begin{array}{c}\text { DEGs Genes with } \\
\text { Pathway Annotation } \\
\text { (1521) }\end{array}$ & $\begin{array}{c}\text { All Genes with } \\
\text { Pathway Annotation } \\
(24,936)\end{array}$ \\
\hline 1 & Terpene biosynthetic process & 7 & 7 \\
\hline 2 & Tricarboxylic acid metabolic process & 20 & 120 \\
\hline 3 & Regulation of defense response & 15 & 77 \\
\hline 4 & Terpene metabolic process & 7 & 19 \\
\hline 5 & Citrate metabolic process & 19 & 119 \\
\hline 6 & Regulation of response to stress & 15 & 84 \\
\hline 7 & Acetate metabolic process & 5 & 18 \\
\hline 8 & $\begin{array}{l}\text { Positive regulation of microtubule } \\
\text { Polymerization or depolymerization }\end{array}$ & 2 & 2 \\
\hline 9 & Metabolic process & 1203 & 19,066 \\
\hline 10 & Lignin metabolic process & 5 & 21 \\
\hline 11 & Apoptotic process & 2 & 3 \\
\hline 12 & Regulation of cell size & 2 & 3 \\
\hline 13 & phenylpropanoid metabolic process & 15 & 128 \\
\hline 14 & Cellular amino acid catabolic process & 6 & 33 \\
\hline 15 & Response to bacterium & 27 & 282 \\
\hline 16 & $\begin{array}{l}\text { Energy coupled proton transmembrane } \\
\text { Transport, against electrochemical gradient }\end{array}$ & 11 & 88 \\
\hline 17 & Nucleoside diphosphate metabolic process & 5 & 26 \\
\hline 18 & Cellular respiration & 11 & 89 \\
\hline 19 & Regulation of multi-organism process & 3 & 10 \\
\hline 20 & Arachidonic acid metabolic process & 2 & 4 \\
\hline
\end{tabular}

Multiple pathways involved in the metabolism of secondary metabolites were enriched, including those related to metabolism of the three main kinds of secondary metabolites: terpenes, phenols, and alkaloids (Table 3). Terpenes are the richest natural production and all of the monoterpenoid, diterpenoid, triterpenoid, and sesquiterpenoid (carotenoid) and terpenoid backbone 
biosynthesis pathways were regulated by Psa infection. Expression of as many as $64(6.92 \%)$ genes in phenylpropanoid biosynthesis pathway which is the key progress in biosynthesis of phenols was regulated. Gene encoding the key enzyme phenylalanine ammonia-lyase (PAL) in phenol biosynthesis was found to be up regulated. Meanwhile, metabolism of the three main intermediate products tryptophan, tyrosine, and phenylalanine of phenol biosynthesis was also influenced. Two pathways in alkaloids biosynthesis were changed but the number of genes regulated only accounted a small part of all the genes annotated.

Table 3. Enriched pathways involved in secondary metabolism.

\begin{tabular}{|c|c|c|c|c|}
\hline Metabolites & Pathway ID & Pathway & $\begin{array}{c}\text { DEGs Genes } \\
\text { with Pathway } \\
\text { Annotation } \\
\text { (925) }\end{array}$ & $\begin{array}{l}\text { All Genes with } \\
\text { Pathway } \\
\text { Annotation } \\
(11,433)\end{array}$ \\
\hline \multirow{7}{*}{ Terpenes } & ko00902 & Monoterpenoid biosynthesis & $8(0.86 \%)$ & $17(0.15 \%)$ \\
\hline & ko00903 & Limonene and pinene degradation & $8(0.86 \%)$ & $32(0.28 \%)$ \\
\hline & ko00904 & Diterpenoid biosynthesis & $8(0.86 \%)$ & $32(0.28 \%)$ \\
\hline & ko00909 & Sesquiterpenoid and triterpenoid biosynthesis & $4(0.43 \%)$ & $17(0.15 \%)$ \\
\hline & ko00906 & Carotenoid biosynthesis & $8(0.86 \%)$ & $51(0.45 \%)$ \\
\hline & ko00905 & Brassinosteroid biosynthesis & $2(0.22 \%)$ & $17(0.15 \%)$ \\
\hline & ko00900 & Terpenoid backbone biosynthesis & $9(0.97 \%)$ & $117(1.02 \%)$ \\
\hline \multirow{7}{*}{ Phenols } & ko00940 & Phenylpropanoid biosynthesis & $64(6.92 \%)$ & $317(2.77 \%)$ \\
\hline & ko00380 & Tryptophan metabolism & $28(3.03 \%)$ & $105(0.92 \%)$ \\
\hline & ko00350 & Tyrosine metabolism & $14(1.51 \%)$ & $86(0.75 \%)$ \\
\hline & ko00360 & Phenylalanine metabolism & $9(0.97 \%)$ & $84(0.73 \%)$ \\
\hline & ko00941 & Flavonoid biosynthesis & $9(0.97 \%)$ & $91(0.8 \%)$ \\
\hline & ko00944 & Flavone and flavonol biosynthesis & $1(0.11 \%)$ & $11(0.1 \%)$ \\
\hline & ko00400 & Phenylalanine, tyrosine and tryptophan biosynthesis & $6(0.65 \%)$ & $89(0.78 \%)$ \\
\hline \multirow{2}{*}{ Alkaloids } & ko00950 & Isoquinoline alkaloid biosynthesis & $7(0.76 \%)$ & $39(0.34 \%)$ \\
\hline & ko00960 & Tropane, piperidine and pyridine alkaloid biosynthesis & $4(0.43 \%)$ & $42(0.37 \%)$ \\
\hline
\end{tabular}

Pathogenesis-related (PR) proteins are thought to participate in plant-defense mechanism. We searched the kiwifruit transcriptomic profile and identified genes encoding PR proteins belonging to 10 families of the all 17 PR protein families (Table 4 and Table S5). We identified the most unigenes in PR-9, PR-5 and PR-14 family with properties of peroxidase, thaumatin-like and lipid-transfer protein respectively. Unigenes belonging to PR-1, PR-4, PR-5, PR-9, PR-10, and PR-12 showed differentially expression in Psa-infected kiwifruit. Meanwhile we also identified genes encoding three kinds of antimicrobial peptides: hevein-like peptide, knottin-type peptide and snakin peptide, of which hevein-like peptide and snakin peptide were regulated by Psa infection.

Table 4. Differentially expressed genes encoding pathogenesis-related proteins.

\begin{tabular}{cccc}
\hline Family & Properties & All Expressed Unigenes & Differentially Expressed Unigenes \\
\hline PR-1 & Unknown & 6 & 2 \\
PR-2 & 3-1,3-glucanase & 1 & 0 \\
PR-4 & Chitinase type I, II & 2 & 1 \\
PR-5 & Thaumatin-like & 39 & 6 \\
PR-6 & Proteinase-inhibitor & 9 & 0 \\
PR-9 & Peroxidase & 96 & 8 \\
PR-10 & "Ribonuclease-like” & 1 & 1 \\
PR-12 & Defensin & 3 & 1 \\
PR-13 & Thionin & 3 & 0 \\
PR-14 & Lipid-transfer protein & 21 & 0 \\
\hline
\end{tabular}

We screened out the resistant genes from the RNA sequencing data by searching the R-Gene database (PRGdb). In total, 4773 resistant genes were identified which could be grouped into 22 classes. The biggest class was RLP which acts as receptors to recognize avirulence genes. Of all the resistant genes identified, expression of 283 was changed by Psa treatment (Table 5). The class with the most differentially expressed resistant genes was NL which holds domains NBS (nucleotide-binding site) 
and LRR (leucine-rich repeat). Classes CN, CNL, N, and TNL also hold the NBS domain. Classes CNL, NL and TNL hold the LRR domain while RLK, RLK-GNK2, and RLP hold an extracellular leucine-rich repeat (eLRR). So, most of the differentially expressed resistant genes hold a NBS domain or a LRR domain. For most of the big classes, a certain number of genes exhibited regulated expression patterns in XJ3. Of the resistant genes, 211 (Table S6) hold the U-box domain and 25 were differentially expressed in Psa infected kiwifruit. Of the 25 differentially expressed U-box domain containing genes, 22 were up regulated in Psa infected kiwifruit and only three down regulated with small extent.

Table 5. The differentially expressed resistant genes.

\begin{tabular}{ccc}
\hline Class & $\begin{array}{c}\text { Number of All Identified } \\
\text { Resistant Gene }\end{array}$ & $\begin{array}{c}\text { Number of Differentially } \\
\text { Expressed Genes }\end{array}$ \\
CN & 123 & 6 \\
CNL & 411 & 25 \\
L & 19 & 0 \\
Mlo-like & 34 & 0 \\
N & 706 & 36 \\
NL & 828 & 69 \\
Other & 93 & 8 \\
PTO & 2 & 1 \\
Pro-like & 74 & 4 \\
RLK & 281 & 20 \\
RLK-GNK2 & 246 & 13 \\
RLK-Kinase & 1 & 0 \\
RLK-Malectina & 1 & 0 \\
RLK-Pro-like & 1 & 0 \\
RLP & 1265 & 60 \\
RLP-Malectin & 5 & 0 \\
RLP-Malectina & 1 & 0 \\
RPW8-NL & 11 & 1 \\
T & 98 & 5 \\
TNL & 572 & 35 \\
TNL-OT & 1 & 0 \\
\hline
\end{tabular}

\subsection{Analysis of Genes in Plant-Pathogen Interaction}

From KEGG analysis, we enriched genes participating in the pathway of plant-pathogen interaction. A total of 593 related genes were identified (Table S2) and they involve almost all of the processes of the plant-pathogen interaction pathway, including PTI, HR, stomatal closure, ETI, and programmed cell death. Of all the 593 plant-pathogen interaction related genes, 59 showed altered expression in Psa treatment (Figure S2). Two DEGs encoding a pattern recognition receptor (PRR) CERK1 were identified, but it belonged to PRRs which recognize chitin PAMPs of fungus. Expression of a protein kinase encoding gene $C D P K$ was also regulated. It plays important roles in regulating gene transcriptional changes and other cellular response. Two transcription factors WRKY25 and WRKY29 also displayed changed expression. They participate in the MAPK (mitogen-activated protein kinase) signal pathway and induce expression of defense-related genes. The other differentially expressed transcription factors were pathogenesis-related genes transcriptional activator Pti1 and Pti4. The PR1 gene which plays an important role in plant disease resistance takes part in multiple biological processes including MAPK signaling pathway, plant hormone signal transduction and plant-pathogen interaction. Its expression change in Psa treatment indicated its disease resistance function. We also identified two differentially expressed disease resistance genes RPM1 and RPS2. They both function with another resistance gene RIN4 and induce hypersensitive response. Expression regulation of the above resistance genes in the plant-pathogen interaction pathway indicates that Psa treatment induced plant immunity and led to functioning of the related resistance genes to protect the plant body. 


\section{Discussion}

Plants are organisms which cannot move like animals and therefore they cannot escape potential threats from environment, including pathogens, arthropods, and abiotic stress. They survive depending on constitutive physical and chemical defense mechanisms such as waxy cuticles, cell walls, and phytoanticipins [13]. Besides these common defense mechanisms, plants also evolve a specific immune system, namely PTI and ETI to defend themselves against various pathogens around them [14]. To successfully infect a plant, pathogens have to penetrate the physical layer and make use of plant nutrition which would induce expression changes of various genes.

Secondary metabolites play important roles in regulation of plant growth and defense to pests and pathogens [15]. Plants deploy numerous secondary metabolites to facilitate interaction with biotic and abiotic environment. In our study, gene expression of the three main kinds of secondary metabolites including terpenes, phenols, and alkaloids were influenced by Psa infection. Terpenes are the largest class of natural products, many of which are toxic to insects [16], fungi [17], and bacteria [18]. Expression changes of genes involved in biosynthesis of monoterpenoid, diterpenoid, triterpenoid, sesquiterpenoid, and terpenoid backbone indicated that terpenes may play an important role in interaction between kiwifruit and Psa. Changes in diterpenoid and triterpenoid were particularly important, for the former is involved in gibberellin biosynthesis, and the latter involved in brassinosteroid biosynthesis. Both of the two plant hormones were found to function in plant innate immunity [19]. Expressions of eight genes related to biosynthesis of carotenoid which is tetraterpene were all increased after Psa infection. Carotenoids are important antioxidants to sweep reactive oxygen species produced by plant under stress [20].

Plant phenols are secondary metabolites with various structures. They work as signal compounds, pigments, internal physiological regulators or chemical messengers, and function in the resistance mechanism of plants against pathogens [21]. Most phenols biogenetically arise from the shikimatephenylpropanoid-flavonoids pathway where phenylalanine ammonia-lyase (PAL) plays the key role in phenols production. Gene expression of $P A L$ was up regulated in a sample infected by Psa meanwhile the phenylpropanoid biosynthesis pathway and phenylalanine metabolism pathway were also influenced. Metabolisms of tryptophan, tyrosine, and phenylalanine which are the mean precursors of phenols were altered as well. The results above indicate that the whole metabolism pathway of phenols was regulated and plant phenols may play an important role in kiwifruit resistance to Psa.

Pathogenesis-related (PR) proteins are induced under various biotic and abiotic stresses. They play an important role in plant-defense mechanism. We identified genes encoding PR proteins belonging to 10 families of the all 17 PR protein families characterized to date [22]. Unigenes belonging to PR-1, PR-4, PR-5, PR-9, PR-10, and PR-12 showed differentially expression in Psa-infected kiwifruit. In another study on kiwifruit by Beatrice [23], PR-1 and PR-5 expression was also induced by Psa. PR-1 proteins act as a molecular marker for systemic acquired resistance response. PR- 5 acts as antifungal; glucanase and xylanase inhibitors; and $\alpha$-amylase and trypsin inhibitors. Its down-regulation leads to susceptibility of resist Piper colubrinum to the oomycete pathogen Phytophthora capsici [24]. PR-4 proteins bind to chitin, and play an important role in enhancing the chitinase activity. The induction of PR4 transcripts in wheat coleoptils and roots is correlated with the expression of the corresponding proteins that are expressed only in the infected tissues [25]. PR-9 catalyzes cross-linking of macromolecules in plant cell wall and produces a free radical like $\mathrm{H}_{2} \mathrm{O}_{2}$ against a wide range of pathogens [26]. PR-12 proteins are small cysteine rich peptides providing protection against a broad range of organisms. They are known to inhibit protein synthesis, enzyme activity and ion channel function [27]. Among these PR proteins, PR-12 protein (defensin) and PR-13 protein (thionin) also act as antimicrobial peptides which are found as host defenses against pathogens and pests in diverse organisms [28]. Genes encoding two other antimicrobial peptides hevein-like peptide and snakin peptide were found to express differentially in Psa-infected kiwifruit. Snakin peptide is involved in plant-pathogen interactions [29] and snaking-Z 
derived from Zizyphus jujube fruits displayed antimicrobial activity against different bacterial and fungal [30].

Most disease resistance genes in plants encode nucleotide-binding site leucine-rich repeat (NBS-LRR) proteins. NBS-LRR proteins are involved in detection of diverse pathogens, including bacteria, viruses, fungi, nematodes, insects, and oomycetes. Expressions of many members of the two subfamilies CNL (CC-domain-containing) and TNL (TIR-domain-containing) of NBS-LRR family were detected in kiwifruit and 70 of them were found to be regulated in the Psa-infected kiwifruit. Meanwhile, most of the differentially expressed resistance genes hold an NBS domain or an LRR domain. The NBS domain is also called NB-ARC (nucleotide binding adaptor shared by NOD-LRR proteins, APAF-1, R proteins and CED4) domain. It is thought to result in conformational changes that regulate downstream signaling [31]. The LRR domain is involved in specific recognition of pathogen effector molecules [32] and it also functions as a regulatory domain [33].

Ubiquitination regulates diverse cellular processes, including floral transition, circadian rhythm, photomorphogenesis, and cell death [34,35]. In the study of Avr9/Cf-9 interaction, Gonzálezlamothe and his colleagues [36] found that two of the three Avr9/Cf-9 Rapidly Elicited (ACRE) genes essential for $C f$-9- and $C f$-4-dependent hypersensitive response encode putative E3 ubiquitin ligase components. Our results identified 211 U-box domain-containing protein encoding genes, of which 25 were differentially expressed in Psa-infected kiwifruit and 22 were up regulated. U-box is a derived version of RING-finger domain that lacks the hallmark metal-chelating residues of the latter but is likely to function similarly to the RING-finger in mediating ubiquitin-conjugation of protein substrates [37,38]. ACRE74 which encodes a U-box E3 ligase homolog was induced in Cf9 tobacco and Cf9 tomato after Avr9 elicitation and its overexpression induced a stronger HR. This shows that the E3 ligase ACRE74 is essential for plant defense and disease resistance. PUB13 (plant U-box protein 13) is a well-studied example in plant disease resistance. Silencing of the PUB13 induced spontaneous cell death, elevated resistance to biotrophic pathogens but increased susceptibility to necrotrophic pathgenes [39]. Another study showed that PUB13 is also involved in regulating the FLS2-mediated PTI [40]. In our study, most of the differentially expressed PUB encoding genes were up regulated by Psa infection in kiwifruit, indicating they may play an important role in the interaction between kiwifruit and Psa.

During the long term of interaction between plants and pathogens, plants have evolved a complete defense system, namely PTI and ETI. This immune system will be triggered by recognition of PAMPs or effector secreted by invading pathogens and induces expression of resistance genes. Meanwhile, pathogens also can escape recognition by plants by lose or change of PAMPs and disturb ETI by new evolved effectors [41]. Approximately 50 pathovars of P. syringae have been recognized [42], and they cause economically important diseases in a wide range of plant species. Psa was first identified in Japan in 1984 [1] and it might evolved from ancestor of other hosts [43]. Transcriptomic analysis of kiwifruit infected by Psa contributes to explore the interaction between Psa and kiwifruit. Expressions of many genes involved in PTI and ETI were detected and several important genes showed differential expression in Psa-infected kiwifruit. CDPK and Rboh were PAMP induced genes which displayed increased expression in Psa-infected kiwifruit. These two genes regulate the production of reactive oxygen species $[44,45]$ which induce HR. WRKY TFs are a large family involved in various plant processes but most notably in coping with diverse biotic and abiotic stresses [46,47]. In this study, four WRKY genes WRKY22, WRKY25, WRKY29, and WRKY33 were all up regulated by Psa infection. WRKY22, WRKY29 and WRKY33 were also found to be up-regulated in Arabidopsis induced by chitin [48]. Overexpression of WRKY 25 resulted in increased disease symptoms to P. syringae infection, possibly by negatively regulating salicylic acid (SA)-mediated defense responses [49]. Two Pti genes were induced by Psa. Pti1 is involved in a Pto-mediated signaling pathway, probably by acting as a component downstream of Pto in a phosphorylation cascade. Its expression in tobacco plants enhanced the hypersensitive response to a P. syringae pv. tabacoo strain carrying the avirulence gene avrPto [50]. Pti4 confers resistance to P. syringae pv tomato that causes bacterial speck disease in tomato [51]. RIN4 in Arabidopsis is targeted by type III effectors AvrRpt2 and AvrRpm1 which inhibit PAMP- 
induced signaling and compromise the host's basal defense system. The R proteins, RPS2 and RPM1 whose encoding genes were regulated by Psa sense type III effectors-induced perturbation of RIN4 and guard the plant against pathogens [52]. One heat shock protein (HSP) encoding gene HSP90 was also down regulated. HSP90 is required for functioning of RPS2 and its inhibition reduces the HR and abolishes resistance against $P$. syringae pv. tomato DC3000 [53].

\section{Materials and Methods}

\subsection{Plant Materials and Treatments}

The kiwifruit (Actinidia chinensis var. deliciosa) cultivar "Jinkui" kept in Institute of Botany, Jiangsu Province and Chinese Academy of Science, China, was used in this study. Shoots of good growth vigor were collected from kiwifruit trees and stuck in MS medium, and maintained in growth chambers. The condition was set with a temperature of $25{ }^{\circ} \mathrm{C}$ and $12 \mathrm{~h} / 12 \mathrm{~h}$ (light/dark) cycles. After one week, seedlings were inoculated with the canker-causing bacteria Pseudomonas syringae pv. actinidiae (Psa). Bacterial cells were suspended in distilled water and adjusted to an $\mathrm{OD}_{600}=0.2$, and injected into the seedling stems which were carved with a knife. Five treatments were set: CK, only carved; PY3, inoculated with water and sampled $48 \mathrm{~h}$ after inoculation; PY4, inoculated with water and sampled at $96 \mathrm{~h} ; \mathrm{XJ} 3$, inoculated with Psa and sampled at $48 \mathrm{~h} ; \mathrm{XJ} 4$, inoculated with Psa and sampled at $96 \mathrm{~h}$. Phloem of each sample was collected with three biological replicates.

\subsection{RNA Extraction, Transcriptome Sequencing and De Novo Assembly}

Total RNA was isolated from phloem samples according the method of Cai [54], and mRNA was enriched by Oligo (dT) bead. Then the enriched mRNA was fragmented into short fragments (approximately 200-700 nt) and reverse transcripted into cDNA with random primers, and then the second-strand cDNA were synthesized. Sequencing was done using Illomina HiSeq ${ }^{\mathrm{TM}} 4000$ by Gene Denovo Biotechnology Co. (Guangzhou, China).

After filtering of low-quality raw reads, transcriptome de novo assembly was carried out with short reads assembling program Trinity [55]. The assembled transcript whose length was larger than $200 \mathrm{bp}$ was kept. The longest transcript in each locus was taken as the unigene.

\subsection{Functional Annotation of Unigenes}

BLASTx program (http:/ / www.ncbi.nlm.nih.gov / BLAST) was used to annotate the unigenes, with an $E$-value threshold of $10^{-5}$ to NCBI non-redundant protein $(\mathrm{Nr})$ database (http:/ / www.ncbi. nlm.nih.gov), the Swiss-Prot protein database (http:/ / www.expasy.ch/sprot), and the COG/KOG database (http: / / www.ncbi.nlm.nih.gov/COG). The best alignment results were for protein functional annotations. GO annotation of unigenes was analyzed by Blast2GO software [56], and functional classification of unigenes was performed using WEGO software [57]. Kyoto Encyclopedia of Genes and Genomes (KEGG) annotations were obtained in http:/ / www.genome.jp/kegg.

For R-Gene analysis, protein coding sequences of unigenes were aligned by BLASTp to R-Gene database PRGdb (http://prgdb.crg.eu/wiki/Main_Page).

\subsection{Functional Analysis of Differentially Expressed Unigenes}

The unigene expression was calculated and normalized to RPKM (Reads Per kb per Million reads) [58]. The edgeR package (http://www.r-project.org/) was used to identify differentially expressed genes (DEGs) between Psa treated sample and control. Genes with a fold change $\geq 2$ and a false discovery rate (FDR) $\leq 0.05$ in a comparison were defined as significant DEGs. All DEGs were mapped to GO terms in the Gene Ontology database (http:/ / www.geneontology.org), and gene numbers were calculated for every term. Significantly enriched GO terms in DEGs comparing to the genome background were defined by hypergeometric test. The rigorous FDR correction method was for $q$ value correction, and GO terms were defined as being significantly enriched when the $q$ value 
was $\leq 0.05$. KEGG pathway enrichment analysis was done to identify significantly enriched metabolic pathways or signal transduction pathways in DEGs comparing with the whole genome background. Pathways with $q$ value $\leq 0.05$ were defined as significantly enriched.

\subsection{Quantitative RT-PCR Analysis}

To test the expression results from transcriptome sequencing, we determined the expression levels of 12 randomly selected unigenes through the method of qRT-PCR. Primers were designed using Primer5 software (Table S7), and AdActin was used as internal control. We performed qRT-PCR using the SYBR ${ }^{\circledR}$ Premix Ex Taq ${ }^{\mathrm{TM}}$ (Perfect Real Time, Dalian, China) (TaKaRa Code: DRRO41A), with PCR conditions of 40 cycles of $95^{\circ} \mathrm{C}$ for $20 \mathrm{~s}, 60^{\circ} \mathrm{C}$ for $20 \mathrm{~s}$, and $72{ }^{\circ} \mathrm{C}$ for $40 \mathrm{~s}$. Relative gene expression was calculated according to the $2^{-\triangle \triangle \mathrm{Ct}}$ method [59].

\section{Conclusions}

In order to explore the interaction between Psa and its host kiwifruit plants, we analyzed the transcriptome of kiwifruit infected by Psa. In total, 8255 differentially expressed genes were identified, including those involved in secondary metabolites metabolism, NBS-LRR protein encoding genes, and genes of plant immunity system PTI and ETI. Expression changes of genes involved in the secondary metabolism especially the biosynthesis of terpenes were evident, indicating the probable role of secondary metabolites in plant defense. Expressions of genes encoding NBS-LRR proteins which are usually products of resistance genes were also found to be regulated. Among these NBS-LRR protein genes, we noted that U-box domain containing genes were obviously differentially expressed. PUB proteins mediate ubiquitin-conjugation of protein substrates, and may function in HR. Expression of genes involved in PTI and ETI was detected and some key genes showed differential expression in Psa-infected kiwifruit. These genes play important roles in plant immunity system, such as PAMP and effector recognition, signal transduction, HR and defense related gene induction. We hope our results will facilitate the future study of interaction between Psa and kiwifruit.

Supplementary Materials: Supplementary materials can be found at www.mdpi.com/1422-0067/19/2/373/s1.

Acknowledgments: This study was funded by the National Natural Science Foundation of China (NSFC) (Grant No. 31401854), the Foundation of Jiangsu Key Laboratory for the Research and Utilization of Plant Resources (Institute of Botany, Jiangsu Province and Chinese Academy of Sciences) (Grant No. JSPKLB201602) and the Natural Science Foundation of Jiangsu Province (Grant No. BK20171328).

Author Contributions: Zhong-Ren Guo and Ji-Yu Zhang designed the experiments. Tao Wang, Ji-Yu Zhang and Gang Wang performed the experiments. Tao Wang, Zhan-Hui Jia, and De-Lin Pan analyzed the data. Tao Wang and Ji-Yu Zhang wrote the manuscript. All authors read and approved the final manuscript.

Conflicts of Interest: The authors declare no conflict of interest.

\section{References}

1. Serizawa, S.; Ichikawa, T.; Takikawa, Y.; Tsuyumu, S.; Goto, M. Occurrence of bacterial canker of kiwifruit in Japan, description of symptoms, isolation of the pathogen and screening of bacteriocides. Jpn. J. Phytopathol. 1989, 55, 427-436. [CrossRef]

2. Vanneste, J.L.; Yu, J.; Cornish, D.A.; Tanner, D.J.; Windner, R. Identification, virulence and distribution of two biovars of Pseudomonas syringae pv. actinidiae in New Zealand. Plant Dis. 2013, 97, 708-719. [CrossRef]

3. Chapman, J.R.; Taylor, R.K.; Weir, B.S.; Romberg, M.K.; Vanneste, J.L. Phylogenetic relationships among global populations of Pseudomonas syringae pv. actinidiae. Phytopathology 2012, 102, 1034-1044. [CrossRef] [PubMed]

4. Vanneste, J.L.; Poliakoff, F.; Audusseau, C.; Cornish, D.A.; Paillard, S. First report of Pseudomonas syringae pv. actinidiae, the causal agent of bacterial canker of kiwifruit in France. Plant Dis. 2011, 95, 1311-1312. [CrossRef]

5. Boller, T.; Felix, G. A renaissance of elicitors, perception of microbe-associated molecular patterns and danger signals by pattern-recognition receptors. Annu. Rev. Plant Biol. 2009, 60, 379-406. [CrossRef] [PubMed] 
6. Alfano, J.R.; Collmer, A. Type III secretion system effector proteins, double agents in bacterial disease and plant defense. Annu. Rev. Phytopathol. 2004, 42, 385-414. [CrossRef] [PubMed]

7. Guo, M.; Tian, F.; Wamboldt, Y.; Alfano, J.R. The majority of the type iii effector inventory of pseudomonas syringae pv. tomato dc3000 can suppress plant immunity. Mol. Plant. Microbe Interact. 2009, 22, 1069-1080. [CrossRef] [PubMed]

8. Chisholm, S.T.; Coaker, G.; Day, B.; Staskawicz, B.J. Host-microbe interactions, shaping the evolution of the plant immune response. Cell 2006, 124, 803-814. [CrossRef] [PubMed]

9. Greenberg, J.T.; Yao, N. The role and regulation of programmed cell death in plant-pathogen interactions. Cell. Microbiol. 2004, 6, 201-211. [CrossRef] [PubMed]

10. Mccann, H.C.; Rikkerink, E.H.A.; Bertels, F.; Fiers, M.; Lu, A.; Reesgeorge, J. Genomic analysis of the kiwifruit pathogen pseudomonas syringae pv. actinidiae provides insight into the origins of an emergent plant disease. PLoS Pathog. 2013, 9, e1003503. [CrossRef]

11. Scortichini, M.; Marcelletti, S.; Ferrante, P.; Petriccione, M.; Firrao, G. Pseudomonas syringae pv. actinidiae: A re-emerging, multi-faceted, pandemic pathogen. Mol. Plant Pathol. 2012, 13, 631-640. [CrossRef] [PubMed]

12. Marcelletti, S.; Ferrante, P.; Petriccione, M.; Firrao, G.; Scortichini, M. Pseudomonas syringae pv. actinidiae draft genome comparisons reveal strain-specific features involved in adaptation and virulence to Actinidia species. PLoS ONE 2011, 6, e27297. [CrossRef] [PubMed]

13. Agrios, G.N. How plants defend themselves against pathogens. In Plant Pathology; Elsevier Inc.: Amsterdam, The Netherlands, 2005; pp. 105-160.

14. Dodds, P.N.; Rathjen, J.P. Plant immunity, towards an integrated view of plant-pathogen interactions. Nat. Rev. Genet. 2010, 11, 539-548. [CrossRef] [PubMed]

15. Bennett, R.N.; Wallsgrove, R.M. Tansley Review No. 72. Secondary metabolites in plant defence mechanisms. New Phytol. 1994, 127, 617-633. [CrossRef]

16. Lee, S.; Peterson, C.J.; Coats, J.R. Fumigation toxicity of monoterpenoids to several stored product insects. J. Stored Prod. Res. 2003, 39, 77-85. [CrossRef]

17. Hammer, K.A.; Carson, C.F.; Riley, T.V. Antifungal activity of the components of Melaleuca alternifolia (tea tree) oil. J. Appl. Microbiol. 2003, 95, 853-860. [CrossRef] [PubMed]

18. Friedman, M.; Henika, P.R.; Mandrell, R.E. Bactericidal activities of plant essential oils and some of their isolated constituents against Campylobacter jejuni, Escherichia coli, Listeria monocytogenes, and Salmonella enterica. J. Food Prot. 2002, 65, 1545-1560. [CrossRef] [PubMed]

19. Bruyne, L.D.; Hfte, M.; Vleesschauwer, D.D. Connecting growth and defense: The emerging roles of brassinosteroids and gibberellins in plant innate immunity. Mol. Plant 2014, 7, 943-959. [CrossRef] [PubMed]

20. Canfield, L.M.; Forage, J.W.; Valenzuela, J.G. Carotenoids as cellular antioxidants. Proc. Soc. Exp. Biol. Med. 1992, 200, 260-265. [CrossRef] [PubMed]

21. Slatnar, A.; Mikulič-Petkovšek, M.; Veberič, R.; Štampar, F. Research on the involment of phenoloics in the defence of horticultural plants. Acta Agric. Slov. 2016, 107, 183-189. [CrossRef]

22. Christensen, A.B.; Cho, B.H.; Næsby, M.; Gregersen, P.L.; Brandt, J.; Madrizordeñana, K.; Collinge, D.B.; Thordal-Christensen, $\mathrm{H}$. The molecular characterization of two barley proteins establishes the novel pr-17 family of pathogenesis-related proteins. Mol. Plant Pathol. 2002, 3, 135-144. [CrossRef] [PubMed]

23. Beatrice, C.; Linthorst, J.M.H.; Cinzia, F.; Luca, R. Enhancement of PR1, and PR5, gene expressions by chitosan treatment in kiwifruit plants inoculated with pseudomonas syringae pv. actinidiae. Eur. J. Plant Pathol. 2017, 148, 163-179. [CrossRef]

24. Anu, K.; Jessymol, K.K.; Chidambareswaren, M.; Gayathri, G.S.; Manjula, S. Down-regulation of osmotin (PR5) gene by virus-induced gene silencing (VIGS) leads to susceptibility of resistant piper colubrinum link. to the oomycete pathogen phytophthora capsici leonian. Indian J. Exp. Biol. 2015, 53, 329-334. [PubMed]

25. Bertini, L.; Leonardi, L.; Caporale, C.; Tucci, M.; Cascone, N.; Berardino, I.D.; Buonocore, V.; Caruso, C. Pathogen-responsive wheat $P R 4$ genes are induced by activators of systemic acquired resistance and wounding. Plant Sci. 2003, 164, 1067-1078. [CrossRef]

26. Hegde, Y.R.; Keshgond, R.S. Role of pathogenesis-related proteins in plant disease management-A review. Agric. Rev. 2013, 34, 145-151.

27. Vriens, K.; Cammue, B.P.; Thevissen, K. Antifungal plant defensins: Mechanisms of action and production. Molecules 2014, 19, 12280-12303. [CrossRef] [PubMed] 
28. Egorov, T.A.; Odintsova, T.I.; Pukhalsky, V.A.; Grishin, E.V. Diversity of wheat anti-microbial peptides. Peptides 2005, 26, 2064-2073. [CrossRef] [PubMed]

29. Bindschedler, L.V.; Whitelegge, J.P.; Millar, D.J.; Bolwell, G.P. A two component chitin-binding protein from french bean-Association of a proline-rich protein with a cysteine-rich polypeptide. FEBS Lett. 2006, 580, 1541-1546. [CrossRef] [PubMed]

30. Daneshmand, F.; Zare-Zardini, H.; Ebrahimi, L. Investigation of the antimicrobial activities of Snakin-Z, a new cationic peptide derived from Zizyphus jujuba fruits. Nat. Prod. Res. 2013, 27, 2292-2296. [CrossRef] [PubMed]

31. Tameling, W.I.; Elzinga, S.D.; Darmin, P.S.; Vossen, J.H.; Takken, F.L.; Haring, M.A.; Cornelissen, B.J. The tomato R gene products I-2 and MI-1 are functional ATP binding proteins with ATPase activity. Plant Cell 2002, 14, 2929-2939. [CrossRef] [PubMed]

32. Luck, J.E.; Lawrence, G.J.; Dodds, P.N.; Shepherd, K.W.; Ellis, J.G. Regions outside of the leucine-rich repeats of flax rust resistance proteins play a role in specificity determination. Plant Cell 2000, 12, 1367-1377. [CrossRef] [PubMed]

33. Tao, Y.; Yuan, F.; Leister, R.T.; Ausubel, F.M.; Katagiri, F. Mutational analysis of the Arabidopsis nucleotide binding site-leucine-rich repeat resistance gene RPS2. Plant Cell 2000, 12, 2541-2554. [PubMed]

34. Yee, D.; Goring, D.R. The diversity of plant U-box E3 ubiquitin ligases, from upstream activators to downstream target substrates. J. Exp. Bot. 2009, 60, 1109-1121. [CrossRef] [PubMed]

35. Craig, A.; Ewan, R.; Mesmar, J.; Gudipati, V.; Sadanandom, A. E3 ubiquitin ligases and plant innate immunity. J. Exp. Bot. 2009, 60, 1123-1132. [CrossRef] [PubMed]

36. Gonzálezlamothe, R.; Tsitsigiannis, D.I.; Ludwig, A.A.; Panicot, M.; Shirasu, K.; Jones, J.D. The U-box protein CMPG1 is required for efficient activation of defense mechanisms triggered by multiple resistance genes in tobacco and tomato. Plant Cell 2006, 18, 1067-1083. [CrossRef] [PubMed]

37. Aravind, L.; Koonin, E.V. The U box is a modified RING finger-A common domain in ubiquitination. Curr. Biol. 2000, 10, R132-R134. [CrossRef]

38. Lorick, K.L.; Jensen, J.P.; Fang, S.; Ong, A.M.; Hatakeyama, S.; Weissman, A.M. Ring fingers mediate ubiquitin-conjugating enzyme (E2)-dependent ubiquitination. Proc. Natl. Acad. Sci. USA 1999, 96, 11364-11369. [CrossRef] [PubMed]

39. Li, W.; Ahn, I.P.; Ning, Y.; Park, C.H.; Zeng, L.; Whitehill, J. The U-box/ARM E3 ligase PUB13 regulates cell death, defense and flowering time in Arabidopsis. Plant Physiol. 2012, 159, 239-250. [CrossRef] [PubMed]

40. Lu, D.; Lin, W.; Gao, X.; Wu, S.; Cheng, C.; Avila, J. Direct ubiquitination of pattern recognition receptor FLS2 attenuates plant innate immunity. Science 2011, 332, 1439-1442. [CrossRef] [PubMed]

41. Zhou, J M.; Chai, J. Plant pathogenic bacterial type III effectors subdue host responses. Curr. Opin. Microbiol. 2008, 11, 179-185. [CrossRef] [PubMed]

42. Gardan, L.; Shafik, H.; Belouin, S.; Broch, R.; Grimont, F.; Grimont, P.A. DNA relatedness among the pathovars of Pseudomonas syringae and description of Pseudomonas tremae sp. nov. and Pseudomonas cannabina sp. nov. (ex Sutic and Dowson 1959). Int. J. Syst. Bacteriol. 1999, 49, 469-478. [CrossRef] [PubMed]

43. Monteil, C.L.; Cai, R.; Liu, H.; Llontop, M.E.; Leman, S.; Studholme, D.J. Nonagricultural reservoirs contribute to emergence and evolution of pseudomonas syringae crop pathogens. New Phytol. 2013, 199, 800-811. [CrossRef] [PubMed]

44. Kobayashi, M.; Ohura, I.; Kawakita, K.; Yokota, N.; Fujiwara, M.; Shimamoto, K. Calcium-dependent protein kinases regulate the production of reactive oxygen species by potato NADPH oxidase. Plant Cell 2007, 19, 1065-1080. [CrossRef] [PubMed]

45. Kurusu, T.; Kuchitsu, K.; Tada, Y. Plant signaling networks involving $\mathrm{Ca}^{2+}$ and Rboh/Nox-mediated ROS production under salinity stress. Front. Plant Sci. 2015, 6, 427. [CrossRef] [PubMed]

46. Eulgem, T. Regulation of the Arabidopsis defense transcriptome. Trends Plant Sci. 2005, 10, 71-78. [CrossRef] [PubMed]

47. Naoumkina, M.; He, X.; Dixon, R. Elicitor-induced transcription factors for metabolic reprogramming of secondary metabolism in Medicago truncatula. BMC Plant Biol. 2008, 8, 132. [CrossRef] [PubMed]

48. Wan, J.; Zhang, S.; Stacey, G. Activation of a mitogen-activated protein kinase pathway in Arabidopsis by chitin. Mol. Plant Pathol. 2004, 5, 125-135. [CrossRef] [PubMed]

49. Zheng, Z.; Mosher, S.; Fan, B.; Klessig, D.; Chen, Z. Functional analysis of Arabidopsis WRKY25 transcription factor in plant defense against Pseudomonas syringae. BMC Plant Biol. 2007, 7, 2. [CrossRef] [PubMed] 
50. Zhou, J.; Loh, Y.T.; Bressan, R.A.; Martin, G.B. The tomato gene ptilencodes a serine/threonine kinase that is phosphorylated by pto and is involved in the hypersensitive response. Cell 1995, 83, 925-935. [CrossRef]

51. Wu, K. Functional analysis of tomato Pti4 in Arabidopsis. Plant Physiol. 2002, 128, 30. [CrossRef] [PubMed]

52. Kim, M.G.; Da, C.L.; Mcfall, A.J.; Belkhadir, Y.; Debroy, S.; Dangl, J.L. Two pseudomonas syringae type III effectors inhibit RIN4-regulated basal defense in Arabidopsis. Cell 2005, 121, 749-759. [CrossRef] [PubMed]

53. Takahashi, A.; Casais, C.; Ichimura, K.; Shirasu, K. HSP90 interacts with RAR1 and SGT1 and is essential for RPS2-mediated disease resistance in Arabidopsis. Proc. Natl. Acad. Sci. USA 2003, 100, 11777-11782. [CrossRef] [PubMed]

54. Cai, B.H.; Zhang, J.Y.; Gao, Z.H.; Qu, S.C.; Tong, Z.G.; Mi, L.; Qiao, Y.S.; Zhang, Z. An improved method for isolation of total RNA from the leaves of Fragaria spp.. Jiangsu J. Agric. Sci. 2008, 24, 875-877.

55. Grabherr, M.G.; Haas, B.J.; Yassour, M.; Levin, J.Z.; Thompson, D.A.; Amit, I. Full-length transcriptome assembly from RNA-Seq data without a reference genome. Nat. Biotechnol. 2011, 29, 644-652. [CrossRef] [PubMed]

56. Conesa, A.; Götz, S.; Garcíagómez, J.M.; Terol, J.; Talón, M.; Robles, M. Blast2GO, a universal tool for annotation, visualization and analysis in functional genomics research. Bioinformatics 2005, 21, 3674-3676. [CrossRef] [PubMed]

57. Ye, J.; Fang, L.; Zheng, H.; Zhang, Y.; Chen, J.; Zhang, Z. WEGO: A web tool for plotting Go annotations. Nucleic Acids Res. 2006, 34, W293. [CrossRef] [PubMed]

58. Mortazavi, A.; Williams, B.A.; Mccue, K.; Schaeffer, L.; Wold, B. Mapping and quantifying mammalian transcriptomes by RNA-Seq. Nat. Methods 2008, 5, 621-628. [CrossRef] [PubMed]

59. Livak, K.J.; Schmittgen, T.D. Analysis of relative gene expression data using real-time quantitative PCR and the 2(-Delta Delta C (T)) method. Methods 2001, 25, 402-408. [CrossRef] [PubMed]

(C) 2018 by the authors. Licensee MDPI, Basel, Switzerland. This article is an open access article distributed under the terms and conditions of the Creative Commons Attribution (CC BY) license (http:/ / creativecommons.org/licenses/by/4.0/). 